\title{
COMPARATIVE NOTES ON VARIOUS NON-BOOK CATALOGING SYSTEMS
}

\author{
by Catlierine Rodriguez-Nieto
}

\section{INTRODUCTION}

During the past twenty years the use of electronic and other non-book learning aids has exploded from tiny experimental programs in a few chosen academic centers into classrooms and laboratories at every level of instruction all over the world. It was inevitable that a tag should develop between the production and acquisition of new types of material, and the establishing of systems for classifying them. Only during the last five or six years have attempts been made to standardize, at least on a national level, the criteria for cataloging non-book materials. In the interim, schools and libraries have either adapted (with varying degrees of success) those for cataloging books, or developed systems based on their particular needs and facilities. The purpose of this article is to provide an idea of some of the various existing systems and, through comparison, of the differences between them and the reasons for those differences. Of the four systems to be examined, two were devised by groups of professional librarians, one for multi-media collections and the other for audio materials only. The others two were developed at educational institutions for highly specialized collections, viz., taped materials for college-level instruction in foreign languages.

The second preliminary edition of the Rules for Descriptive Cataloging in the Library of Congress: Phonorecords appeared in 1964, and was designed to supplement the rules for cataloging visual materials. This was the only authority available for cataloging audio materials until 1968, when the Department of Audio-Visual Instruction, National Education Association, in Washington, D.C., published its Standards for Cataloging, Coding and Scheduling Educational Media. This edition contained reports from two groups of researchers, the first giving rules for conventional cataloging of twenty-three types of nonbook media, the second for computerizing cataloging data for these media. The first revision of the booklet appeared in 1971, under the title Standards for Cataloging Nonprint Materials, published by the Association for Educational Communications and Technology. In this edition the rules for computerizing information were eliminated. Those for conventional cataloging were brought much more closely into line with the Anglo-American Cataloging Rules, and the examples (including reproductions of actual cards) were increased to constitute a special section in which each type of medium was treated separately. The third edition, which was published in 1972, reflects new developments in the audio-visual field, while embodying the principles set forth in the second. In the table following this article, references to 
computer methods are from the first edition, all others from the third edition. ${ }^{1}$

The Summer, 1966, issue of the Audio-Visual Language Journal contained an article describing the system developed at the Royal College of Advanced Technology in Salford, England, for cataloging taped language lessons. It should be noted that the system has undoubtedly, in the intervening years, undergone some changes. The nature of the collection and the ways in which the problems encountered in cataloging it were met, however, offer some interesting points of comparison and contrast with relation to the cataloging system devised and currently in use at the Language Laboratory of the University of California, Berkeley. In the following discussion reference will be made to all four systems, though primary emphasis will be on the last. The table at the end is a point-by-point summary and comparison of the four.

Since its inception in 1960 , the Language Laboratory at the University of California, Berkeley, has acquired a collection of taped material in fifty-seven languages, including English. At present our holdings comprise 5,000 ten-inch master recordings. Over 6,200 seveninch copies of those recordings are available for students to use in the laboratory, and some $\mathbf{9 0 0}$ five-inch reels may be checked out for home use.

In addition to language lessons, the collection includes lectures, poetry readings, phonetic studies and other items less directly related to language learning. Since cataloging the lesson materials was of primary concern, however, the system outlined in this article was designed for those materials.

The need for a catalog became apparent quite soon after the Language Laboratory began operating, but devising a workable one proved a long and difficult process. Work was begun by Robert Krones and carried on by Carol Crowther under the direction of Jesse 0 . Sawyer; the system as it exists now was initiated by Glen M. Grosjean with assistance from Martin Morrison, and given its present form by Catherine Rodriguez-Nieto. ${ }^{2}$

'For a summary of several newly developed systems in computerized multi-media cataloging, see Lucius Butler and Robert L. Liske, "Classifi." cation and Coding Systems for Media Resources," in AV Communication Review, Fall 1972.

2Our "Tape Cataloging Manual (Preliminary Edition, 1971)" is available through this journal, or may be had by writing to: Language Laboratory, B-40 Dwinelle Hall, University of California, Berkeley, California 94720. 
In a sense, we had some advantages. We were interested in cataloging only tapes, and the tapes were either recorded in the Laboratory to uniform physical specifications, or transferred from publishers' originals to the same specifications. Master recordings were-and are-prepared at 7.1/2 inches per second, full track, on high-quality tape and stored post.wound on hubs in ten-inch boxes. Leader is spliced onto both ends and between lessons or other subdivisions, which are separated by ten seconds or so of forty-cycle tone as well. ${ }^{3}$

These masters are used only for duplication. The library copies produced from the masters are on seven-inch reels, also recorded at 7-1/2 inches per second, but only on the upper track, leaving the lower track free for student recording. Lending copies are on five-inch reels, recorded at 3-3/4 inches per second, or cassettes, and the containers are marked to indicate speed and upper-track or two-track recording. For the French laboratory classroom. special four-track cassettes are prepared, with one lesson track and one student track on each "side."

Since the same recording may exist in several physical forms, each designed for a specific use, no physical description is given on the catalog cards. It seems likely, however, that we will soon need to mark the cards in some way to indicate all the existing forms of each recording. Both the Library of Congress (hereafter referred to as LC) and the Association for Educational Communications and Technology (AECT) systems are designed to accommodate material differing greatly in physical format. Both therefore include pains." taking physical description of each object so that people consulting the catalog will know what kind of equipment they will need in order to use the material. At the Royal College of Advanced Technology (RCAT), masters and student copies alike are recorded on five-inch reels of tape at 3-3/4 inches per second. Therefore the RCAT system, and that of the Language Laboratory at the University of California, Berkeley (UCBLL) are alike in that they do not provide for physical description.

Another advantage at UCBLL was that, with very few exceptions, all the material was for college-level instruction. Unless otherwise noted, most leson series are elementary. In the few cases where more advanced material cannot be spotted by title, some notation is made on the card, usually in the final paragraph.

3See Robert Grones, Jesse O. Sawyer and Glen M. Grosjean, "On the Use of Low-Frequency Tones for Marking Language Laboratory Tapes," in Language Learning, Vol. XIV, No. 1, pp. 51-54. 
LC and AECT are designed for material varying in level from pre-school through adult; accordingly, each provides distinguishing, at a glance, the age group or other special category involved. LC, of course, uses a call number; AECT, in addition to a Dewey or LC call number, uses a Maturity Range code.

In spite of the physical uniformity and specialized nature of our collection, the project was difficult, first because of the diversity of content in the recorded materials to be cataloged, and second, because there were virtually no guidelines available. Most manuals on nonbook cataloging had a section on sound recordings which dealt only, or at least primarily, with phonodiscs and/or music. Now and then an article would appear in a journal describing the attempts to solve problems similar to ours at other institutions; but these involved smaller collections and were fitted to different methods of use. Only after several experiments was a system devised that we felt was consistent enough for easy use, yet flexible enough to accommodate rather detailed information about various types of materials.

\section{Catalog Cards}

Experience showed that the criteria for book cataloging satisfied the needs of neither the staff nor the faculty and student users of the Language Laboratory. The cards were time consuming to prepare and often lacked necessary information but contained elements (e.g., tracings) which served no practical purpose.

The first step in revising the system, then, was re-designing the cards. After the first revision, only one file was kept, consisting of a blue cover card and white time cards for each series. 4 Under the present system there are three files of three-by-five Rolodex cardsone for student use in the Tape Library, one in the Tape Librarian's office, and one in the Duplication Service room. Each file contains an identical, color-coded cover or entry card for every series (blueon order; green-in process; yellow-completed; orange-incomplete but closed; pink-insufficiently documented or of uncertain format). Bibliographical and other information is summarized on these cards from various worksheets filled out at the time a series is being produced. In addition, the file used by the Duplication Service staff contains white "time cards" on which is entered the time of each lesson or other division within a series which has been definitively cataloged. The cards for a series are found in only one place in the catalog; no added entries are used.s

"In the UCBLL system, the word "series" applies to a set of recordings considered as a separate production. It may be lesson material, a play, a set of examinations, or a collection of readings or songs, etc.

sSee Sample Card section following Bibliography at the end of this article. 


\section{Tape Identification}

For a time call numbers were used which consisted of course numbers and authors' initials. As the collection grew it became evident that course numbers and assigned materials were subject to frequent change, and that a more permanent and less confusing locator device was needed. Limited subject matter, however, made impractical the use of Dewey or LC numbers. A three-part identification for each series was settled on finally, which would consist of the first three letters of the name (in English) of the language, followed by a title and a three-digit accession number, beginning with 001 for each language. This identification would appear on every card and every tape box and reel, and also on all paperwork related to that series. Both cards and library tapes would be filed alphabetically by language, and within language by series title. Duplication masters would be stored, within language, by accession number. When asking for a tape, a student need remember only the title (in most cases) of his textbook, yet the three-letter language code and the accession number could serve the functions of a call number for Laboratory staff members.

This method has, in fact, proved most satisfactory.

\section{Title}

Assigning a title is, of course, an important part of cataloging, and is rarely as simnle as it would seem to be. Nevertheless, several formulae have evolved which expedit the work and keep confusion to a minimum. At UCBLL, choice of a series title depends on several factors.

It should correspord as closely as possible to that of the written material the tapes accompany, it should be short enough to remember easily, and also to fit on the spine of the tape box. It should, in the case of two or more series for the same text or literary work, or for different texts with similar titles, be distinctive. If the written material is unpublished or compiled from several sources, the series title should be descriptive:

\section{Intermediate Readings}

When the taped material for a book has been divided for convenience into, say, dialogues and drills, two separate series result:

\section{Modern Spanish-Dialogues$$
\text { Modern Spanish-Grammar }
$$

If it is possible to determine that recorded material is designed to supplement, rather than accompany, a book, the word "Supplementary" is included in the title unless the writer has given it a title of its own. Of course, the degree of correspondence between tapes and 
texts varies widely; sometimes a taped series produced by the publisher of a book is specifically advertised as being based on the material in the book, not a repetition of it. In such a case, since this is the official set of tapes, it bears simply the book title.

Examinations related to a textbook are given the book title followed by the word "Examinations"; diagnostic and other examinations are assigned descriptive titles.

Except for anonymous works, which are cataloged by title, the series title for a literary work begins with the author's surname:

Claudel: Christophe Colomb

Originally it was decided that two works by the same author would be listed after the surname in the series title:

Laforet: Al colegio and Rosamunda

but that a descriptive word or phrase would be used if the series contained three or more works. In practice this has proven awkward because of the length of the titles (which are difficult to fit into the space available on labels, cards, etc.), and unnecessary because the items are numbered. Three alternatives present themselves-make two separate series, add a third item, or change the rule!

We try to include works by only one author (or one set of joint authors) in a series. If, however, works by two different authors are included, both authors are listed, but no titles are given regardless of the number of works, a descriptive word or phrase is used instead.

Laforgue and Apollinaire: Poems

Both of two joint authors are given:

Il'f and Petrov: Tonia

Works by three or more different authors are treated as anthologies and given a descriptive title, excluding authors' names. When a significant part (half or more) of a published anthology is recorded, the series bears the book title; otherwise, the series is given a descrip. tive title and the source noted in the first paragraph on the entry card.

Lectures are cataloged under the lecturer's surname, followed by the title he has given, or by a collective title if several lectures are included in the series.

The title of a series of songs is usually similar to that of an anthology. Whenever appropriate, the writer's name is included:

\section{Bellman: Songs}

AECT differs from traditional rules in using title as the main entry in most cases. Both AECT and LC use the title found on the object cataloged, or assign a title which appears in brackets on the card, and both provide notes explaining title source if other than the object itself. Both also use ample cross-reference, with added entries for co-authors, title, subject headings and certain performers or other contributors. AECT catalogs separately each of two or more titles on 


\section{Comparative Notes}

a tape or phonodisc album, listing others in a note. (This is apparently done only when the works have been issued without a collective title, in which case the practice parallels that of LC). Subtitles follow the title or appear in the contents note. At the Royal College for Advanced Technology (RCAT), a title is not used for identifying the tapes, but the title for a textbook used with the tapes is noted on the cards.

\section{Bibliographical Information}

It is this writer's opinion (founded on several years' experience) that basic information is the most difficult to come by. In acquiring a series of tapes from a publisher, the author, title and year of the text recorded or supplemented on tape can usually be found with relative ease by means of Books in Print or by a letter directly to the publisher. In cataloging a locally produced series, however, this in. formation must be elicited by a number of carefully framed questions, often through telephone calls and notes. We have instituted a policy requirirg that a copy be supplied, prior to any actual recording, of the text or script for each series to be included in the Language Laboratory collection. This policy, of course, insures much more than the information mentioned above, and enhances the usefulness of a series for students working individually, as well as for instructors.

The first paragraph on the card, then, lists the source of the recorded material, whether published or unpublished. For textbooks, author(s), title, subtitle and imprint are given. For a published anthology, we formerly gave a list of contents in addition to the above only if the selections were not listed by number in the table of contents of the book (e.g., A. Sonnenfeld, ed., 36 French Pcems). Since in practice this causes some inconvenience, we will in the future list items in any anthology, whether published or not. by author and title. Author and title are given for literary works, and the edition is noted whenever possible. A special effort is made to secure and note information about the edition recorded when it is a simplified or annotated version.

In this respect, the UCBLL system differs considerably from LC and AECT, which give information about other versions or previous editions, variant titles, probable dates, etc. The article outlining the RCAT system contained only very general remarks about documenting the written source of taped material, but some provision is definitely made.

\section{Contents}

The second paragraph on the UCBLL card indicates how manyand, if necessary, which-lessons or other numbered parts have been 
recorded for the series. It summarized the list of lessons or parts on the time card and provides (together with the "Total time" paragraph immediately following it) an idea of the length, and some clue to the scope, of the series. In the case of an unpublished anthology of a collection of songs, this paragraph is telescoped with the first or replaces it.

The LC "Contents" note for audio material is determined in the same way as that for visual material, and may be combined with performer notes for collections. AECT lists the titled parts of a work, following a fifty-word summary of the content. RCAT maintains one card for each tape, with an index of all the drills (number, type and purpose of each) on the tape.

\section{Total Time}

At UCBLL, the total time of a series is given in hours, minutes and seconds on the entry card. This is most useful, particularly to people wishing to order copies of the tapes, since the cost is directly based on the timed length of the series. As was mentioned above, the time for each lesson is entered on white "time cards" filed behind the entry card in the Duplication Service file. This is helpful for students who need to order only part of a series, and also to instructors in scheduling laboratory work.

LC gives the playing time of a phonorecord only if it appears on the object cataloged, along with other elements in the collationnumber of items, measurements, playback speed, etc. AECT includes running time in the physical description of the object cataloged, and also gives, if it is easily available, the time of each work in a collection. Although RCAT gives the length (in minutes?) of each tape, drills are not separately timed.

\section{Date, Place of Recording}

The date and place of recording are given for all local UCBLL series, and for others when possible, except for commercial lesson series, which are presumably made about the time the book is published or shortly after. The notation then reads simply "Publisher's tapes." For phonodiscs, the imprint (including label, disc or album number and series, if any) is given here. Place is not given for phonodiscs, and the recording date is given only if it is of some importance, e.g., for the performance of a play, or for a very old recording. 


\section{Comparative Notes}

LC gives place only if the publisher is not primarily of phonorecords, and performance or recording date only if it is easily available. AECT provides as many dates as possible for production, release, original versions, etc., but has no specific rules for performance date. RCAT gives the recording date on each card, but apparently only for locally produced lesson series.

\section{Participants}

For a lesson series produced at UCBLL, up to three speakers are noted if there are more than three, only the first or principal speaker is given on the card, followed by "et al.," though all are listed on the origination sheets. (Participants' names are rarely available for commercially produced lesson tapes.) For plays, whether locally produced or not, director, producer and cast (including each member's role) are all listed as completely as possible; for music, soloists, accompanists, groups (but not members of groups) and directors are listed as completely as possible.

LC always gives the names of performers or participants, though dramatic casts are limited to the names of the actors playing the first notes may be combined for a collection of works published under a five leads (roles not given); as noted above, performer and contents collective title, and some separately catalogued works may have added entries under performers' names. AECT makes optional the listing of credits-performers or other contributors-but specifies that, if listed, they should follow the order of listing on the object catalogued. RCAT gives the speaker of the drills on each tapes but makes no mention of other participants.

\section{Format}

The sixth paragraph on the UCBLL entry card is something of a "catch-all" in which points about the numbering system or the nature of the series are clarified. What is included here depends largely on the type of series and any difficulties that might be encountered in using it.

The paragraph opens with information about pauses, if any, and the arrangement and general purpose of the various parts of the lessons, examinations, etc. If necessary, and explanation of the numbering system follows, then a list of review lessons and/or lessons for which no material has been recorded, and any notations of missing portions or serious defects which cannot be remedied. For non-lesson material, an attempt is made to give, in brief form, as much additional information as seems useful, and to place it historically, usually by 
century. Instrumental accompaniment or interludes are noted (except in full productions of plays) and, in the case of pre-recorded material, the existence of any booklet which accompanies the source.

Some of this information is given by LC and AECT in separate notes. though the details UCBLL gives about the lesson material are suited to the needs of students in the Language Laboratory. RCAT, as noted, lists each drill by type and purpose. No statement is made, however, as to whether or not additional details are given.

\section{Restrictions}

The last item on the UCBLL card is purely administrative, and has no parallel in any of the other systems examined. Since copyright restrictions on taped material are subject to change, they are entered in pencil on the back of the entry card.

On the whole, our system as it now exists is workable. We are planning, when time and funds permit, to supplement the card catalog with an index file, in particular for series dealing primarily with grammar. Of more immediate concern, however, is the cataloging of taped materials other than language lessons, and of films.

As may be seen from the above, elements of cataloging information are given in roughly the same order under the LC, AECT and UCBLL systems, although not all elements are common to all the systems, and the emphasis placed on each varies according to the needs of the catalog users. Although most of the principal elements were mentioned in the RCAT article, no samples of actual cards were available. The two outstanding characteristics of RCAT-extensive use of codes for identification and location, and detailed indexing, on both tapes and cards-are, it would seem, feasible only for a very small collection. This system shares with UCBLL a relatively narrow range in level and subject of instruction, a lack of physical description (made possible by uniform preparation of tapes) and explicit provision for maintaining a file of written material corresponding to the taped material. Whereas the RCAT indexing of drills on both tapes and cards is by no means undesirable, the UCBLL system of tones and timing works extremely well as a locator device, and seems preferable if a choice is to be made.

One extremely important characteristic, shared by all four systems, is flexibility. Acknowledgement is freely made of the necessity of change to meet new developments in a constantly expanding field.

Comments or suggestions regarding any part of this article would be most welcome. 


\begin{tabular}{|c|c|c|c|c|}
\hline \multirow{2}{*}{$\begin{array}{l}\text { ORDER OF } \\
\text { CATALOGING } \\
\text { ELEMENI'S }\end{array}$} & Title & Classification numbers & Language code & Language code \\
\hline & Medium & Author & Series title & $\begin{array}{l}\text { Material code } \\
\text { (e.g., syntax) }\end{array}$ \\
\hline & Edition & Physical Medium & Accession number & Series code \\
\hline & $\begin{array}{l}\text { Producer-Sponsor } \\
\text { Releasing agent }\end{array}$ & Title & $\begin{array}{l}\text { Author(s), title, } \\
\text { edition, imprint }\end{array}$ & $\begin{array}{l}\text { Lesson, drill num- } \\
\text { bers }\end{array}$ \\
\hline & Date of release & Imprint & Contents & $\begin{array}{l}\text { Source } \\
\text { (bibliographical) }\end{array}$ \\
\hline & Physical description & Collation & Duration & Date of recording \\
\hline & Series & $\begin{array}{l}\text { Notes (including series, } \\
\text { participant, edition, } \\
\text { duration, contents, etc.) }\end{array}$ & $\begin{array}{l}\text { Date, place of } \\
\text { recording }\end{array}$ & Speaker \\
\hline & $\begin{array}{l}\text { Educational level } \\
\text { and/or Special } \\
\text { Audience }\end{array}$ & & Participant(s) & Duration \\
\hline & $\begin{array}{l}\text { Notes (including summary } \\
\text { and contents) }\end{array}$ & & Format & Index of drills \\
\hline & $\begin{array}{l}\text { Tracings } \\
\text { Classification numbers }\end{array}$ & & Copyright, cost of copy & \\
\hline $\begin{array}{l}\text { SIZE OF } \\
\text { COLLECTION }\end{array}$ & $\begin{array}{l}\text { Various system suitable } \\
\text { for very large collection. }\end{array}$ & $\begin{array}{l}\text { Various; system suitable } \\
\text { for very large collection. }\end{array}$ & $\begin{array}{l}\text { Moderately large; } 57 \text { lan- } \\
\text { guages represented. }\end{array}$ & $\begin{array}{l}\text { Small; } 5 \text { languages } \\
\text { represented. }\end{array}$ \\
\hline
\end{tabular}




\begin{tabular}{|c|c|c|c|c|}
\hline PURPOSE & $\begin{array}{l}\text { Audio-visual instruction, } \\
\text { all subjects, all levels. }\end{array}$ & $\begin{array}{l}\text { Audio reproduction, all } \\
\text { subjects, all levels. }\end{array}$ & $\begin{array}{l}\text { Language instruction, } \\
\text { college level. }\end{array}$ & $\begin{array}{l}\text { Language instruc- } \\
\text { tion, college level. }\end{array}$ \\
\hline MEDIUM & $\begin{array}{l}23 \text { types of audio-visual } \\
\text { material. }\end{array}$ & 7 types of phonorecords. & $\begin{array}{l}\text { Magnetic tape recordings } \\
\text { (uniform specifications); } \\
4,700 \text { permanent masters, } \\
6,700 \text { quasi-permanent } \\
\text { reels for student use in } \\
\text { laboratory, } 650 \text { for use } \\
\text { in home. }\end{array}$ & $\begin{array}{l}\text { Magnetic tape rc- } \\
\text { cordings (uniform } \\
\text { specifications); } \\
\text { permanent masters, } \\
\text { on permanently } \\
\text { recorded reels for } \\
\text { student use. }\end{array}$ \\
\hline $\begin{array}{l}\text { SOURCES OF } \\
\text { COLLECTION }\end{array}$ & Various. & Various. & $\begin{array}{l}\text { Local faculty, laboratory } \\
\text { staff; commercial } \\
\text { suppliers. }\end{array}$ & $\begin{array}{l}\text { Local faculty, lab- } \\
\text { oratory staff; } \\
\text { commercial suppli- } \\
\text { ers. }\end{array}$ \\
\hline $\begin{array}{l}\text { USERS OF } \\
\text { CATALOG }\end{array}$ & $\begin{array}{l}\text { General public; instruc. } \\
\text { tors, all levels; library } \\
\text { staff. }\end{array}$ & $\begin{array}{l}\text { General public, instruc- } \\
\text { tors. all levels; library } \\
\text { staff. }\end{array}$ & $\begin{array}{l}\text { Students and faculty (UC } \\
\text { and other); laboratory } \\
\text { staff. }\end{array}$ & $\begin{array}{l}\text { Students, faculty } \\
\text { of Royal College, } \\
\text { laboratory staff. }\end{array}$ \\
\hline $\begin{array}{l}\text { FILING } \\
\text { Cards }\end{array}$ & $\begin{array}{l}\text { Alphabetically by title, } \\
\text { subject headings, author } \\
\text { if applicable. }\end{array}$ & $\begin{array}{l}\text { Alphabetically by author, } \\
\text { title, subject heading. }\end{array}$ & $\begin{array}{l}\text { Alphabetically by language; } \\
\text { within language by series } \\
\text { title, lesson number (orig- } \\
\text { ination and work sheets by } \\
\text { accession number within } \\
\text { language). }\end{array}$ & $\begin{array}{l}\text { Alphabetically by } \\
\text { language; within } \\
\text { language by subjecl } \\
\text { code, series number } \\
\text { tape number (sep- } \\
\text { arate box for each } \\
\text { language). }\end{array}$ \\
\hline Materials & $\begin{array}{l}\text { Call number, media code } \\
\text { if used (see below, } \\
\text { Marking). }\end{array}$ & Call number. & $\begin{array}{l}\text { Library copies as above for } \\
\text { cards; masters as above for } \\
\text { origination and work sheets, } \\
\text { books and scripts by author } \\
\text { or series title within } \\
\text { language. }\end{array}$ & $\begin{array}{l}\text { Tapes and scripts } \\
\text { as above (several } \\
\text { ring-folders for } \\
\text { each language). }\end{array}$ \\
\hline
\end{tabular}




\section{MARKING}

On cards

Conventional-2-letter

media code suggested for

use if necessary as loca.

tor device. Computer-

Not specified.

\section{MARKING}

On materials

Conventional-2-letter

media code, if used on

card, as shelving aid.

INFORMATION ON Conventional-Call number; CATALOG CARDS:heading composed of title, Identification subtitle, type of medium, edition, producer-sponsor. distributor, year. Added entries for author, var jant titles, subject, certain participants; separate entry for each of two or more works on tape or disc (presumably if published without collective title).

dentification number composed of letter code for media, numbers for storage, year, sequence, print/copy; fixed field of 11 characters.
Call number; main entry under author or composer (birth, death dates given) added entries under title. subject headings, perform ers (individuals or groups but not members of groups separate entry for each of two or more works published

Color-coding to indicate state of completion of taped material.

Color.coding by language family (approximate) on reels, boxes; lesson times on boxes; English blurbs, 40-cycle tone on tapes.

Tape identification composed of 3-letter language code, series title and 3 digit accession number: series title begins with author's surname for litwithout collective title.
Color-coding by language on reels, scrip folders, card boxes English blurbs on tapes.

Tape nomenclature composed of capital letters for language nature of material Roman numerals for added series, Arabic numerals for lessons, lower case letters for drills. 


Description
Bibliograph-
ical

Conventional-See above;

if work is part of a series

this is noted following the

physical description. Com-

puter-Full title for cata.

loging, reduced to 20 or 25

characters for sheduling;

producer in 6-letter field

publisher in 4 , place in 4

( 2 for country, 2 for city).

Title, edition, imprint as

for visual material; for

phonodises, imprint includes

album) numbers, but place

only if publisher is not

.

\section{Description}

Physical

\section{duration}

\section{$\ddot{\omega}$}

Other:

level
Conventional-Number of Medium statement in italics objects cataloged, length in minutes if applicable, measurements, playback following title; collation,

jects, measurements, play-

other information back speed (may be supplenecessary for use (derived mented by notes).

from checklist).

Computer-for audio, 3-

digit field; for video,

3-letter field.

Conventional-Maturity

range code or note of

special audience follows

series notation.

Computer - one or more of

10 possible letter desig.

nations.

Conventional-See above, Physical Description;

times for separate parts

given if easily available.

Computer-not coded.
See above, Indentification (call number).

Given in note if stated on object cataloged. publisher, serial (disc or

primarily of dises.

Author(s), title, subtitle,

edition, imprint of printed

material tapes accompany;

information about unpub-

lished material if availa-

ble; list of contents for

unnumbered or unpublished

anthology; for phonodises,

imprint includes only publisher, disc or album num. bers.
Given in last paragraph only if not evident from title, edition, etc.
Information about written source of taped material (presumably including author, title, imprint).
May be indicated by Roman numeral in tape nomenclature; usually evident in dril number.

Length of tape (presumably in minutes) for each numbered parts, total time of series stated on cover card; time for each lesson or other numbered part listed on time card for faculty, laboratory staff use. tape but not for each drill, lesson or whole series. 


\begin{tabular}{ll}
\hline participant/ & Conventional-see below, \\
performer & Contents. \\
& Computer-not coded.
\end{tabular}

Always given in note,
which may be combined
with "Contents" note for with "Contents" note above, Identification.

Other:

production/ performance date

\begin{tabular}{|c|c|}
\hline & $\begin{array}{l}\text { performance date not spec- } \\
\text { ified. } \\
\text { Computer-see above, Iden- } \\
\text { tification for year of } \\
\text { production or release; } \\
\text { performance date not spec- } \\
\text { ified. }\end{array}$ \\
\hline $\begin{array}{l}\text { contents, } \\
\text { other notes }\end{array}$ & $\begin{array}{l}\text { Conventional- } \\
\text { Notes are included as } \\
\text { applicable above physical } \\
\text { description, accompanying } \\
\text { material, title source, } \\
\text { title variations, other } \\
\text { versions of work, credits } \\
\text { (optional); } 50 \text {-word sum- } \\
\text { mary of contents; } \\
\text { tracings. } \\
\text { Computer-not coded. }\end{array}$ \\
\hline
\end{tabular}

Given in note if easily available. Conventional-for years of
production or release, see
above, Identification;

performance date not spec.

tification for year of production or release; performance date not spec-

Conventional-

"Contents" note as for visual materials; other notes list details about series, source of title (if not found in object cataloged), text (lan. guage, author), edition; "with" note for 2 or mor works issued without co lecture title; tracings.
Computer-not coded.
Always given for local

productions, for others if

possible; for plays, direc-

tors, producers, casts (in.

cluding roles) listed; for

music, soloists, groups and directors of groups only.

Always given for local productions, for others when easily available.

\section{Always given (at least for local productions).} performers also listed).
Nature of material given in Index of drills, "Format" paragraph. which giving number ard may also include notes on numbering if lessons, historical period of literary works, musical elements, existence of booklet. Current copyright information entered in pencil on back of cover card.

nature of each.
Speaker given (pre. sumably singers, other 


\section{BIBLIOGRAPHY}

Butler, Lucius and Robert L. Liske, "Classification and Coding Systems for Media Resources," AV Communication Review, Vol. XX, No. 3, Fall, 1972, pp. 296-306.

Catalog, 1970-1972 (Boulder, Colorado: National Center for Audio Tapes).

Catalog of Audio Recordings, 1972 (Chicago: Audio Information Service, University of Illinois at Chicago Circle).

Cataloging Committee of AECT, William J. Quinly, Chairman. Standards for Cataloging Nonprint Materials, rev. ed. (Washington, D.C.: Association for Educational Communications and Technology, 1971).

Hicks, Warren B. and Alma M. Tillin. Developing Multi-Media Libraries (New York: R. R. Bowker Company, 1970).

Information Science Committee of AECT, William J. Quinly, Chairman. Standards for Cataloging Nonprint Materials, 3rd ed. (Washington, D.C.: Association for Educational Communications and Technology, 1972).

Krones, Robert, Jesse O. Sawyer and Glen M. Grosjean. "On the Use of Low-Frequency Tones for Marking Language Laboratory Tapes," in Language Learning, Vol. XIV, No. 1, pp. 51-54.

Riddle, Jean, et al. Non-Book Materials: The Organization of Integrated Collections (Ottawa: Canadian Library Association, 1970).

Rules for Descriptive Cataloging in the Library of Congress: Phonorecords, 2nd prelim. ed. (Washington, D.C.: Library of Congress. 1964).

Sager, J. C. "Cataloguing and Administering a Tape Collection for the Language Laboratory," in Audio-Visual Language Journal, Vol. 4, No. 1, Summer, 1966, pp. 20-23.

Standard for Cataloging, Coding and Scheduling Educational Media (Washington, D.C.: Department of Audio-Visual Instruction, National Education Association, 1968). 